\title{
CONVERGENCE OF SOCIOECONOMIC PROGRESS ACROSS INDIAN STATES
}

\section{SAHIL RAVGOTRA}

PhD Scholar, Centre for Economic Studies and Planning, Jawaharlal Nehru University, New Delhi, India

ABSTRACT
This paper examines the issue of convergence of various socioeconomic indicators among Indian states. The
study is comprehensive in the sense that it does not only concentrate on Income convergence, convergence of human
development across Indian states has also been tested. In fact, the conditional income convergence has also been
assessed wherein different social indicators have been incorporated in the model as control variables. The parametric
panel regression results do not conform conditional and unconditional income divergence, but convergence of human
development has been found significant.
KEYWORDS: Convergence, Human Development, Socioeconomic Indicators, Panel Regression JEL Classification:
E24, O1, A14, C23

Received: Jun 10 2017; Accepted: Jun 23 2017; Published: Jun 23 2017; Paper Id.: IJECRAUG20172

\section{INTRODUCTION}

Regional inequality has always been a major concern of Indian economy. Even though the country has experienced high economic growth, this growth has not been uniform across the states. These regional inequalities are limited not only to the domain of economic indicators, but have also been reflected in the uneven human development among the states during this period. In terms of per capita income some states such as Goa, Delhi and Haryana perform a lot better than states such as Bihar with the difference between them being massive. The regional inequalities are very stark for human development indicators also. From the perspective of evaluating welfare implications and redistributive policies of the policy makers and to achieve social equality, rectifying these inequalities has become all the more important. The question that we are trying to answer in this paper is whether the poor performing states have been able to reduce the difference between them and high performing states.

The paper attempts to answer this question by using the convergence analysis which is well known in macroeconomic analysis. In this paper, we will test for Absolute Beta convergence and Sigma convergence by running parametric panel regressions. If low performing states tend to grow faster than high ones we say that there is absolute $\beta$ convergence. The concept of sigma convergence implies that the states are converging in the sense of sigma and their dispersion tends to decrease over time. The two of them are of course related, but sigma convergence does not necessarily imply Beta convergence.

This paper is organized as follows. Section II provides an overview of studies on convergence across Indian states. Section III describes the data and methodology used in the paper. Section IV is divided into two parts; first discusses the results from income convergence and second discusses the results from human development convergence.

\section{LITERATURE REVIEW}


The idea of convergence was buried in the conventional treatment of growth model by Robert Solow. The topic has been explored in a number of studies. Most of these studies have tested convergence in economic growth across Indian states, covering different time periods.

Dholakia (1994) analyzed convergence of per capita Net State Domestic Product (PCSNDP) growth rates across 20 Indian states during the period 1960-61 to 1989-90. He observed tendencies of convergence in long-term PCSNDP growth rates across the states. Cashin and Sahay (1996) also examined convergence of per capita income for 20 states covering the period 1961-91. They found that there has been absolute $\beta$-Convergence of per capita income across the states during this period. On the contrary, Marjit et al. (1998) investigated convergence in 'properly measured real PCSNDP' for the period 1960-61 to 1994-95 across 26 Indian states. They argued that Indian states diverged in economic growth during 1960-61 to 1994-95.

Nagraj et al. (1998) showed the existence of conditional convergence among 14 states during 1970-1994, but they ruled out the existence of any absolute convergence. They explained inter-state variations in steady states in terms of variations in different factors like physical, economic and social infrastructure. Trivedi (2002) also reached a similar conclusion as Nagaraj et al (1997) and Aiyar (2001) by testing convergence hypothesis of levels and growth rates of per capita income among 16 states during 1960-1992. He asserted that no evidence is found to support absolute $\beta$-Convergence in the growth rates, but confirmed that there is clear and robust evidence for conditional convergence. Rao et al. (1999) based on their analysis of interstate differences in growth rates during 1965-1995 among 14 major states conclude that interstate disparities are increasing rather than converging. These interstate disparities in income are attributed to the differential capacity of the states in attracting private investment and further it is pointed out that the allocation of private investment is determined by the availability of better infrastructure in a state (Rao et al., 1999).

Bhattacharya and Sakthivel (2004) analyzed interstate income disparities before and after the reform period. They showed that interstate income disparities almost remained unchanged during 1980s, but sharply increased during the 1990s. Kar and Sakthivel (2007) argued that regional inequality remained stable without much increase during the 1980s due to a fall in inequality within the industrial and the service sectors during this period. Further, rise in regional inequality in the post-1990s is attributed to a sharp rise in disparity in the industrial and service sectors' progress across the states. Another study by Ghosh (2011) also confirmed an increase in the interstate inequality of per capita income in the post-reform period since 1991.

In this context, this study tries to complement the existing studies in understanding regional inequalities and convergence not only when measured in terms of per capita SNDP, but also in terms of broader range of socio-economic indicators by evaluating the performance of Indian states in socioeconomic indicators during the period of 1971-2011.

\section{DATA AND METHODOLOGY}

The data for per capita state domestic product from 1971-2011 was extracted from RBI'S Handbook of Statistics on Indian Economy. The data on urbanization which is defined as the percentage of population living in urban areas, was sourced from database of Ministry of Statistics and Programme Implementation. The data on poverty ratio (head count ratio), infant mortality ratio (number of deaths per 1000 live births) and total fertility rate (the average number of children that are born to a woman over her lifetime) has been mined from various reports of the Planning Commission. The growth rates of the population were available in the Population Census of India, 2011. Ginicoefficient, the measure of inequality 
was appropriated from 'Study of State Finances: State Budgets' Reserve Bank of India database. Development expenditure as a proportion of state's GDP was given in the annual survey of 61st round, NSSO. The source of state-wise literacy rates was Economic Survey, 2011-12, Office of the Registrar General of India. HDI values for the respective states were extracted from National Human Development Report 2001, Planning Commission and UNDP (India). RBI's occasional papers on inclusive growth and regional dimension were mined for the data for sectoral contribution to NSDP for each state.

For testing the convergence, parametric panel regression was run and states' codes were set as panel variable and time variable was from 1981 to 2011.

\section{Income Convergence}

Sigma Convergence for per capita income was tested by estimating the following regression:

$$
\sigma t=\alpha+\beta t
$$

Where,

$\sigma t=$ sigma of log of per capita income of states at time t.

$\mathrm{t}=$ time

In this case, we are regressing the dispersion of log of per capita income of states against time. We would want the sign of $\beta$ to be negative to prove convergence. The negative sign would imply that there is decrease in dispersion and the inequality has reduced.

Absolute Beta convergence for per capita income was tested by estimating the following regression:

$\ln \left[\frac{Y_{i, t+k}}{Y_{i, t}}\right]=a+b \ln Y_{t, t}+\varepsilon_{t, t}$

Where,

$\ln \left[\frac{Y_{t, t+k}}{Y_{t, t}}\right]$ is the growth rate of per capita income between $\mathrm{t}$ and $\mathrm{t}+\mathrm{k}$

$\ln Y_{t_{s}}$ is the logarithm of the state i's per capita income at time $t$.

So, an absolute $\beta$ convergence test is done for the per capita income, wherein the growth rate of the per capita income, in a particular year is regressed on the log value of the per capita income 10 years earlier. Again over here also we would want the sign of $b$ to be negative, if want to prove convergence. The negative sign would imply that the low per capita income states tend to grow faster than high ones and we say there is absolute $\beta$ convergence.

Conditional Convergence for per capita income was tested by estimating the following regression:

$$
. \ln \left[\frac{Y_{i, t+k}}{Y_{i, t}}\right]=\alpha+\beta_{1} \ln Y_{i, t}+\beta_{2} \operatorname{dev} x_{i, t}+\beta_{3} h d i_{i, t}+\beta_{4} p o p_{i, t}+\varepsilon_{i, t}
$$

Where,

$\ln \left[\frac{Y_{i, t+k}}{Y_{i, t}}\right]$ is the growth rate of per capita income between $\mathrm{t}$ and $\mathrm{t}+\mathrm{k}$ 
$\ln Y_{i, t}$ is the logarithm of the state i's per capita income at time $t$.

dev $x_{t, t}$ is the Development Expenditure of state $\mathrm{i}$ at time $\mathrm{t}$.

$h d i_{t, t}$ is the Human development index of state $\mathrm{i}$ at time $\mathrm{t}$.

pop $p_{t, t}$ is the decadal population variation.

The conditional $\beta$ convergence regression for the log per capita income, with control variables like level of urbanization, proportion of development expenditure, HDI, TFR, IMR, decadal variation in population, contribution of primary, secondary and tertiary sectors to the net state domestic product, gini coefficient of per capita consumption expenditure, poverty ratio andpercentage change in literacy was run. But finally we have accepted the above stated variables as our final control variables. Please note here that the variables that are decadal in nature like Level of urbanization, Proportion of development expenditure, HDI, TFR, Percentage change in literacy, IMR, Decadal Variation in Population, Primary, Secondary and Tertiary sector's contribution to Net state domestic product, gini coefficient and poverty ratio, their base year values have been taken as the values of these variables.

\section{HDI Convergence}

Sigma Convergence for human development index was tested by estimating the following regression: $\sigma t=\gamma+\delta t$

Where,

$\sigma t=$ sigma (dispersion) of HDI values at time $\mathrm{t}$

Procedure for testing hdi convergence is similar to income convergence procedure. Dispersion of log of hdi values is regressed against time. We would want the sign of $\delta$ to be negative to prove convergence. The negative sign would imply that there is decrease in dispersion and the inequality has reduced.

Absolute Beta convergence for per capita income was tested by estimating the following regression:

$\ln \left[\frac{h d t_{l, t+k}}{h d i_{t, t}}\right]=\varphi+\omega \ln h d i_{i, k}+\varepsilon_{i, t}$

Where,

$\ln \left[\frac{h d i_{l, t-k}}{h d t_{l, k}}\right]$ is the growth rate of human development index between $\mathrm{t}$ and $\mathrm{t}+\mathrm{k}$.

$\ln h d i_{l_{2}}$ is the logarithm of the state i's human development index at time t.

Again, to test the absolute beta convergence in terms of hdi we will regress the growth rate of hdi between two periods against log of hdi values in base year. We would want the sign $\omega$ to be negative if want to prove convergence. The negative sign would imply that the low hdi tend to grow faster than high ones and we say there is absolute $\beta$ convergence.

\section{INTERPRETATION OF THE RESULTS}

The sigma convergence on log of state-wise per capita income (year 1971 to 2011) for 15 states included in the panel reports a reduction in dispersion over time. Annexure 1.1 can be referred for the results of this regression. The $\beta$ coefficient of the time variable (-.0064257) for this regression has a negative sign and is significant at 0.01 level of significance. The model also has a high goodness of fit, R- squared being 0.92 . This reduction in dispersion does not 
necessarily imply convergence because the value of $\sigma t$ at a particular point of time can be higher than its long-term value, for example shocks to output. Subsequently the value of sigma falls to its long run value which is assumed to be unchanged.

Next we tested for absolute beta convergence and the results related to this can be found in annexures 1.2 and 1.3. This exercise is done for the period 1981-2011, using the annual data for the state wise per capita income (year 1971 onwards). A bivariate model with fixed effects was used to run the regression after conducting the hausman test, which reported a highly significant chi 2 statistic ( $\mathrm{p}$ value of chi2 $=0.000)$, suggesting the use of a fixed effects model. The coefficient of the log of the per capita income (.3080007) has a positive sign and is significant at 0.01 level of significance. But the low R-squared (0.23) shows that the model does not have reasonable explanatory power. The regression does not support the absolute convergence hypothesis.

For the data used, the per capita income does not show any conditional convergence, when the controls like proportion of development expenditure to the net state domestic product, HDI and decadal variation in the population are introduced. Annexure 1.4 can be referred for the results of this regression. The coefficient of the log of per capita income has negative sign but it is highly insignificant. The variable proportion of development expenditure to the netstate domestic product has a positive coefficient suggesting the positive impact of development expenditure on the growth rate of the per capita income; however, the coefficient is insignificant at 0.1 level of significance. HDI also has a positive coefficient (1.452317), significant at 0.01 level of significance, again indicating that a rise in human development has progressive impact on the growth rate, the decadal variation in population has a negative coefficient (-.0084714), which is significant at 0.01 level of significance. This brings about the fact that a high population growth will have depressing effect on the growth rate of the per capita income. R-squared (0.35) shows some improvement over the absolute convergence model, however, it says that even this model lacks explanatory power. So, even the conditional convergence for per capita income does not hold, in this case.

The conditional $\beta$ convergence regression for the log per capita income, with control variables like level of urbanization, proportion of development expenditure, HDI, TFR, IMR, decadal variation in population, contribution of primary, secondary and tertiary sectors to the net state domestic product, gini coefficient of per capita consumption expenditure, poverty ratio and percentage change in literacy was run (Annexure 1.5). This model was checked for autocorrelation by conducting the Wooldridge test. The test reported an F statistic significant at 0.01 level of significance, showing the presence of autocorrelation (Annexure 1.6).

Another conditional $\beta$ convergence regression for per capita income was run after correcting for autocorrelation. This regression took proportion of development expenditure to the net state domestic product and the percentage change in literacy as control variables (Annexure 1.7). The model has an R-squared of 0.54, a considerable improvement over the previous regressions. The $\beta$ coefficient of the log of per capita income has a negative sign (-.9639926) and is significant at 0.01 level of significance, supporting the hypothesis of conditional convergence. The proportion of development expenditure to the net state domestic product has a positive coefficient (.0241378), significant at 0.01 level of significance, suggesting that a rise in the development expenditure raises the rate of growth of per capita income. The variable, percentage change in literacy also has a positive coefficient (.0296768), significant at 0.01 level of significance. This clearly shows the positive impact of change in literacy on the growth rate of income per capita. So, the regression after correcting for autocorrelation supports conditional convergence for per capita income. 
Sigma and absolute $\beta$ convergence was tested for HDI also. The data on HDI is decadal in nature. Sigma convergence for HDI for the period 1981-2011 suggests reduction in dispersion in HDI across states over time (Annexure 1.8). The coefficient of the time variable in this regression is negative (-.0365261) and highly significant at 0.01 level of significance. The model has a high R-square of 0.963.

The absolute $\beta$ convergence test for HDI was done by regressing growth of HDI in a particular decade on the log of its value at the beginning of that decade, taking the fixed effects approach (Annexure 1.9). The hausman test reported a chi 2 statistic significant at 0.01 level of significance, suggesting the use of fixed effects model (Annexure 1.10). The coefficient of $\log$ of HDI is negative (-.3629074) and highly significant at 0.01 level of significance indicating convergence in terms of human development among Indian states. The model has R-squared value of 0.7647 indicating that it has high goodness of fit.

\section{CONCLUSIONS}

The objective of this paper is to test convergence hypothesis across 15 major states in India, based on state wise per capita income and HDI. Parametric regressions like absolute, conditional beta convergence and sigma convergence have been used on the data to test convergence.

The study reports interesting findings. For the period 1981-2011, no catching up process is evident for the per capita income. The data does not support convergence hypothesis even when certain social indicators are introduced as controls. So, the study does not reveal any absolute or conditional convergence for per capita income. However, sigmaconvergence for this economic indicator exists. The dispersion in per capita income across states has been reducing overtime. The results highlight the fact that diminishing returns to capital do not apply in every case and there can be other factors that counteract this effect.

Human development Index on the other hand shows absolute beta and sigma convergence. So, there is a clear convergence in HDI.

Overall, the pattern of economic progress in the Indian states support divergence rather than the beta convergence hypothesis while parametric regressions for HDI support convergence hypothesis.

The interesting finding is that the improvement in per capita income witnessed by a few states has not really trickled down to the laggard states while the progress in the status of education and health for the overall economy has led to an improvement in human development of the laggard states.

\section{REFERENCES}

1. Nayak, P.K., Chattopadhyay, Sadhan Kumar, Kumar, Arun Vishnu andDhanya, V. (2010) "Inclusive growth and its regional dimensions, " RBIOccasional Papers.

2. Kalra, Sanjay and Sodsriwiboom, Piyaporn, (2010), "Growth convergence andspillovers among Indian states: What matters? What does not?”(IMFWorking Paper, 2010)

3. Hossain, Akhtar (2000), “Convergence of per capita output levels across regionsof Bangladesh, 1982-87”(IMF Working Paper,2000)

4. Roy, Hiranmoy and Bhattacharya, Kaushik (2009), “Convergence of humandevelopment across Indian states"IGIDR Proceedings/Project Reports Series.

5. Goli, Srinivas, Perianayagam, Arokiasamy and Bhemeshwar, Reddy (2013), "Socio-economic progress across the major 
Indian states: Converging orDiverging?,” MPRA Paper No. 48978, posted 10. August 2013.

\section{ANNEXURES}

Sigma Convergence for PCY

Table 1

\begin{tabular}{|c|c|c|c|}
\hline Source & SS & Df & MS \\
\hline Model & 1.96366168 & 1 & 1.96366168 \\
\hline Residual & 0.15483895 & 39 & 0.003970229 \\
\hline Total & $\mathbf{2 . 1 1 8 5 0 0 6 3}$ & $\mathbf{4 0}$ & $\mathbf{0 . 0 5 2 9 6 2 5 1 6}$ \\
\hline
\end{tabular}

Table 2

\begin{tabular}{|l|c|}
\hline \multicolumn{1}{|c|}{$\mathbf{F}(\mathbf{1 , 3 9})$} & $\mathbf{4 9 4 . 6 0}$ \\
\hline Prob $>$ F & 0.000 \\
\hline R Sqr. & 0.9269 \\
\hline Adj R Sqr & 0.9250 \\
\hline
\end{tabular}

Table 3

\begin{tabular}{|l|c|c|}
\hline $\begin{array}{c}\text { Log of Variance } \\
\text { Across States in a }\end{array}$ & Coefficient & P> l t l \\
\hline given year & & \\
\hline Time & -0.018496 & 0.000 \\
\hline Cons & 2.478593 & 0.000 \\
\hline
\end{tabular}

Hausman Specification Test

Table 4

\begin{tabular}{|c|c|c|c|c|}
\hline & Fixed & Random & Difference & S.E. \\
\hline & & & & \\
\hline $\log (\mathrm{pcy}, \mathrm{t})$ & 0.3080007 & 0.0224376 & 0.2855631 & 0.0227669 \\
\hline & & & & \\
\hline
\end{tabular}

Absolute Beta Convergence Regression, Fixed Effects

Table 5

\begin{tabular}{|l|l|}
\hline R sq ( within) & $\mathbf{0 . 2 3 5 6}$ \\
\hline R sq (between) & 0.4723 \\
\hline R sq (overall) & 0.0651 \\
\hline
\end{tabular}

Table 6

\begin{tabular}{|l|c|}
\hline Corr $\left(\mathbf{u} \_\mathbf{i}, \mathbf{x}\right)$ & $\mathbf{- 0 . 9 7 6 8}$ \\
\hline Prob> F & 0.000 \\
\hline F $(1,449)$ & 138.42 \\
\hline
\end{tabular}

Table 7

\begin{tabular}{|l|c|c|}
\hline Log $(\mathbf{p c y}, \mathbf{t}+\mathbf{k} / \mathbf{p c y}, \mathbf{t})$ & Coefficient & P > ltt \\
\hline $\log ($ pcy, t) & 0.3080007 & 0.000 \\
\hline cons_ & -1.400168 & 0.000 \\
\hline
\end{tabular}

Table 8

\begin{tabular}{|l|l|}
\hline Sigma_u & $\mathbf{0 . 5 2 0 7 2 5 2 5}$ \\
\hline Sigma_e & 0.14136797 \\
\hline Rho & 0.93135631 \\
\hline
\end{tabular}


Test for Beta Conditional Convergence

Table 9

\begin{tabular}{|l|l|}
\hline \multicolumn{1}{|c|}{ R sq (within) } & $\mathbf{0 . 3 5 5 8}$ \\
\hline R sq (between) & 0.3803 \\
\hline R sq (overall) & 0.3013 \\
\hline
\end{tabular}

Table 10

\begin{tabular}{|l|c|}
\hline \multicolumn{1}{|c|}{ Corr $\left(\mathbf{u} \_\mathbf{i}, \mathbf{x}\right)$} & $\mathbf{- 0 . 5 9 6 5}$ \\
\hline F $(4,446)$ & 61.59 \\
\hline Prob $>$ F & 0.000 \\
\hline
\end{tabular}

Table 11

\begin{tabular}{|l|c|c|}
\hline \multicolumn{1}{|c|}{$\log ($ Pcy, $\mathbf{T + K} /$ Pcy T) } & Coefficient & P $>$ Ltl \\
\hline Log (pcy t) & -0.158518 & 0.735 \\
\hline Proportion of development & 0.0093467 & 0.132 \\
\hline expenditure to NSDP & & \\
\hline HDI & 1.452317 & 0.000 \\
\hline Decadal variation in population & -0.0084714 & 0.008 \\
\hline growth rate & & \\
\hline Cons & -1.1122264 & 0.687 \\
\hline
\end{tabular}

Table 12

\begin{tabular}{|l|l|}
\hline Sigma_u & $\mathbf{0 . 1 0 6 5 0 4 4 2}$ \\
\hline Sigma_e & 0.13021371 \\
\hline Rho & 0.40083648 \\
\hline
\end{tabular}

\section{Conditional Convergence Regression 1}

\section{Table 13}

\begin{tabular}{|l|c|c|}
\hline \multicolumn{1}{|c|}{ Log (pcy, t+k/ pcy,t) } & Coefficient & P > lttl \\
\hline Log (pcy, t) & -0.0162612 & 0.739 \\
\hline Level of urbanization & -0.0015176 & 0.769 \\
\hline $\begin{array}{l}\text { Proportion of development expenditure } \\
\text { to NSDP }\end{array}$ & 0.0212017 & 0.006 \\
\hline HDI & & \\
\hline TFR & 4.229637 & 0.000 \\
\hline Percentage change in literacy rates & 0.1189562 & 0.008 \\
\hline & -0.0071515 & 0.427 \\
\hline IMR & & \\
\hline $\begin{array}{l}\text { Decadal variation in population growth } \\
\text { rates }\end{array}$ & 0.002845 & 0.000 \\
\hline & -0.0102716 & 0.006 \\
\hline Primary sector's contribution to NSDP & -0.1624309 & 0.015 \\
\hline & & \\
\hline $\begin{array}{l}\text { Secondary sector's contribution to } \\
\text { NSDP }\end{array}$ & -0.1643394 & 0.014 \\
\hline & & \\
\hline Tertiary sector's contribution to NSDP & -0.1637979 & 0.015 \\
\hline & & 0.156 \\
\hline Gini coefficient & 0.0083907 & 0.720 \\
\hline Poverty ratio & 0.0011378 & 0.034 \\
\hline Cons & 14.13383 & \\
\hline & & \\
\hline
\end{tabular}


Table 14

\begin{tabular}{|l|l|}
\hline \multicolumn{1}{|r|}{ R sq (within) } & \multicolumn{1}{c|}{$\mathbf{0 . 4 2 5 6}$} \\
\hline R sq (between) & 0.1937 \\
\hline R sq (overall) & 0.1961 \\
\hline Corr( u_i, $x)$ & -0.7990 \\
\hline F $(13,417)$ & 23.76 \\
\hline Prob $>$ F & 0.000 \\
\hline Sigma_u & 0.17202037 \\
\hline Sigma_e & 0.12611436 \\
\hline Rho & 0.65041128 \\
\hline
\end{tabular}

Wooldridge Test for Auto-correlation

Table 15

\begin{tabular}{|c|c|}
\hline Ho & $\begin{array}{c}\text { No First Order auto- } \\
\text { Correlation }\end{array}$ \\
\hline F $(1,14)$ & 11.030 \\
\hline Prob> F & 0.0050 \\
\hline
\end{tabular}

Conditional Convergence after Correcting for Auto-correlation

Table 16

\begin{tabular}{|l|c|}
\hline \multicolumn{1}{|c|}{ R sq (within) } & $\mathbf{0 . 5 4 1 1}$ \\
\hline R sq (between) & 0.2199 \\
\hline R sq (overall) & 0.0100 \\
\hline
\end{tabular}

Table 17

\begin{tabular}{|l|l|}
\hline \multicolumn{1}{|c|}{ Corr $\left(\mathbf{u} \_\mathbf{i}, \mathbf{x}\right)$} & \multicolumn{1}{|c|}{$\mathbf{0 . 9 7 1 3}$} \\
\hline F $(4,446)$ & 161.91 \\
\hline Prob> F & 0.000 \\
\hline
\end{tabular}

Table 18

\begin{tabular}{|l|c|c|}
\hline \multicolumn{1}{|c|}{$\log (\mathbf{p c y}, \mathbf{t}+\mathbf{k} / \mathbf{p c y} \mathbf{t})$} & Coeffecient & P >ltl \\
\hline Log (pcy t) & -0.9639926 & 0.000 \\
\hline $\begin{array}{l}\text { Proprtion of development expenditure } \\
\text { to NSDP }\end{array}$ & 0.241378 & 0.006 \\
\hline Percentage change in literacy rates & 0.0296768 & 0.003 \\
\hline Cons & 6.284523 & 0.000 \\
\hline
\end{tabular}

Table 19

\begin{tabular}{|l|l|l|}
\hline Rho ar & $\mathbf{0 . 9 6 6 4 0 3 1 6}$ & \\
\hline Sigma_u & 1.3762057 & \\
\hline Sigma_e & 0.08042512 & \\
\hline Rho fov & 0.99659642 & \\
\hline
\end{tabular}

Sigma Convergence for HDI

Table 20

\begin{tabular}{l|l|l|l} 
Source & SS & df & MS \\
\hline
\end{tabular}




\begin{tabular}{|l|l|l|l|}
\hline Model & 0.006670779 & 1 & 0.006670779 \\
\hline Residual & 0.000254817 & 2 & 0.000127408 \\
\hline Total & $\mathbf{0 . 0 0 6 9 2 5 5 9 6}$ & $\mathbf{3}$ & $\mathbf{0 . 0 0 2 3 0 8 5 3 2}$ \\
\hline
\end{tabular}

Table 21

\begin{tabular}{|l|c|}
\hline \multicolumn{1}{|c|}{ F (1,2) } & $\mathbf{5 2 . 3 6}$ \\
\hline Prob> F & 0.0186 \\
\hline R sq & 0.9632 \\
\hline Adj R sq & 0.9448 \\
\hline
\end{tabular}

Table 22

\begin{tabular}{|l|l|l|}
\hline \multicolumn{1}{|c|}{$\begin{array}{c}\text { Log of Variance } \\
\text { Across }\end{array}$} & Coefficient & P >ltl \\
\hline states given year & & \\
\hline Time & -0.0365261 & 0.019 \\
\hline Cons & 0.2550859 & 0.003 \\
\hline
\end{tabular}

\section{Hausman Test for HDI}

\section{Table 23}

\begin{tabular}{|l|c|c|c|c|}
\hline & Fixed & Random & Differences & S.E. \\
\hline Log $($ HDI, t $)$ & 0.3629074 & 0.2762715 & 0.0866899 & 0.0278279 \\
\hline
\end{tabular}

Testing for absolute HDI Convergence, Fixed Effects

Table 24

\begin{tabular}{|l|c|}
\hline R sq (within) & $\mathbf{0 . 7 6 4 7}$ \\
\hline R sq (between) & 0.8954 \\
\hline R sq (overall) & 0.7401 \\
\hline
\end{tabular}

Table 25

\begin{tabular}{|l|l|}
\hline \multicolumn{1}{|c|}{$\mathbf{F}(\mathbf{1}, \mathbf{2 9})$} & \multicolumn{1}{|c|}{$\mathbf{4 4 . 2 4}$} \\
\hline Corr $\left(\mathrm{u} \_\mathrm{i}, \mathrm{x}\right)$ & -0.6789 \\
\hline Prob> F & 0.000 \\
\hline
\end{tabular}

Table 26

\begin{tabular}{|l|c|c|}
\hline $\begin{array}{c}\text { Log ( HDI,t+k/ } \\
\text { HDI,t) }\end{array}$ & Coefficient & P >ltt \\
\hline Log ( HDI, t) & -0.3629074 & 0.000 \\
\hline Cons & -0.1889678 & 0.000 \\
\hline
\end{tabular}

Table 27

\begin{tabular}{|l|l|}
\hline \multicolumn{1}{|c|}{ Sigma_u } & $\mathbf{0 . 0 3 1 3 8 6 3 4}$ \\
\hline Sigma_e & 0.03969697 \\
\hline Rho & 0.38466266 \\
\hline
\end{tabular}

